\title{
Leak from the vaporizer- An unusual cause
}

Editor- Modern day vaporizers are reliable and come with many safety features. But still human errors are inevitable. We report an incident of an unusual leak from the vaporizer unit. A 40 year old $50 \mathrm{~kg}$ female was undergoing an open cholecystectomy under general anaesthesia. She was the $3^{\text {rd }}$ case on the surgical list. Penlon Sigma Delta isoflurane vaporizer was refilled during the $2^{\text {nd }}$ case. Patient was induced intravenously and anaesthesia was maintained with $60 \%$ nitrous oxide, $40 \%$ oxygen and $1 \%$ isoflurane. After 10 minutes we noticed that inspiratory mean $\mathrm{CO}_{2}\left(\mathrm{imCO}_{2}\right)$ was $18 \mathrm{mmHg}$ and end tidal $\mathrm{CO}_{2}$ $\left(\mathrm{EtCO}_{2}\right)$ was $42 \mathrm{mmHg}$. (Figure 1) Patient was being ventilated with the penlon S2 ventilator via closed circuit. Ventilator settings were 400 $\mathrm{ml}$ tidal volume, 12/min respiratory rate and inspiratory to expiratory ratio $1: 2$. Fresh gas flow (FGF) was $2 \mathrm{~L} / \mathrm{min}$ with oxygen: nitrous oxide ratio of 40:60. Soda lime was checked and found to be fresh. The difference between inspired and exhaled tidal volume was not significant. Monitor showed a MAC value of 0.4 with isoflurane vaporizer dial setting of $1 \%$. FGF was increased, but did not result in change in $\mathrm{imCO}_{2}$. Connections within and between the circuit, the common gas outlet and filler cap of the vaporizer were checked for leaks. We found that the filler plug of the vaporizer was hanging down and the clamp screw was loose. (Figure 2) Some of the FGF was leaking through that window. After the filler plug was repositioned and clamp screw tightened, the problem was rectified. Vaporizer had been filled during the $2^{\text {nd }}$ case by OT attendant. Probably filler plug was loosely placed but not enough to cause a FGF leak during the $2^{\text {nd }}$ case. During the $3^{\text {rd }}$ case the thread of filler plug was probably pulled inadvertently and it fell down as clamp screw was not tightened adequately.

In case of a leak in the vaporizer, the anaesthesia machine can function normally if the vaporizer remains switched off. On switching on the vaporizer, the fresh gas flow is reduced with little or no vapor. A common cause of leak is failure to replace the filler cap or tighten it. ${ }^{1}$ If an incorrect cap is used on a filler device, leak may occur. ${ }^{2}$ Another common cause is absent or damaged O-ring. ${ }^{3}$ Other locations for leaks are loose clamp screw, selector valve, mounting mechanism, interlock device, vaporizer inlet, or outlet connections. Lewis and Andrews reported of a fresh gas flow leak due to loose clamp screw through a Penlon Sigma Elite vaporizer when used on an Ohmeda Modulus II anaesthesia machine. ${ }^{4}$ They recommended that anaesthesia care provider should check the low pressure system for leaks using a negative- pressure leak test after vaporizers are refilled and also after vaporizers are switched out. ${ }^{4}$ Modern anaesthesia machines are capable of performing self testing procedure, which in some cases may eliminate the need for conventional negative- pressure leak testing. However, these tests may not detect internal vaporizer leak on systems with add-on vaporizers. With the self tests to detect an internal leak in the vaporizer, the leak test must be repeated with each vaporizer's dial turned on. When its dial is set in the off position, it may not be possible to detect major internal leaks such as absent or loose filler cap. ${ }^{5}$ In our case leak was due to loose clamp screw that led to falling down of filler plug. This resulted in increase in $\mathrm{imCO}_{2}$ and $\mathrm{EtCO}_{2}$ without loss of tidal volume. Consequences of leaks include alteration in the flow and composition of inspiratory gas and pollution of the operating room air. The former can cause hypoxia, re-breathing or awareness in a patient if not identified and rectified. We did not check the machine after the vaporizer was refilled. If the self testing were employed after the vaporizer was refilled, such incident would not have happened.

Our incident is to reinforce the fact that one should check the low pressure system for leaks using a negative- pressure leak test after vaporizers are refilled and also with vaporizer 
concentration dial turned on. Operator's manual instructs the user to close the fill valve and to fully insert and tighten the filler-port plug in place after filling; anaesthesia care providers need to be aware of the consequences of not following this instruction.

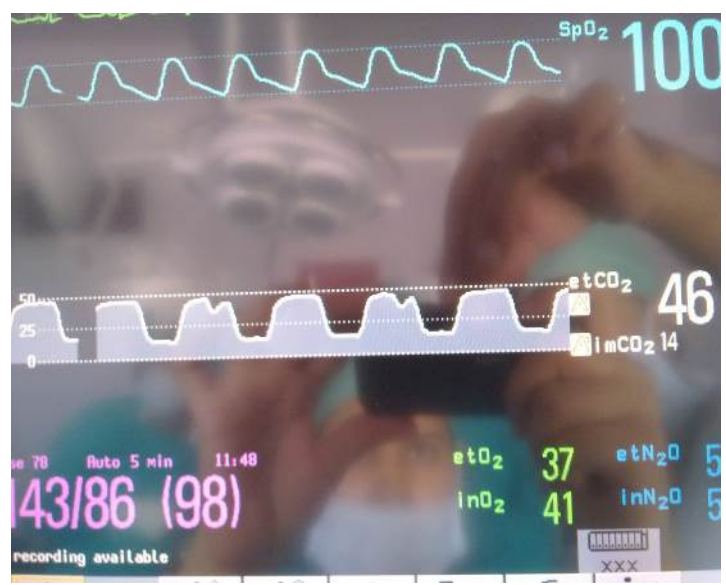

Figure 1

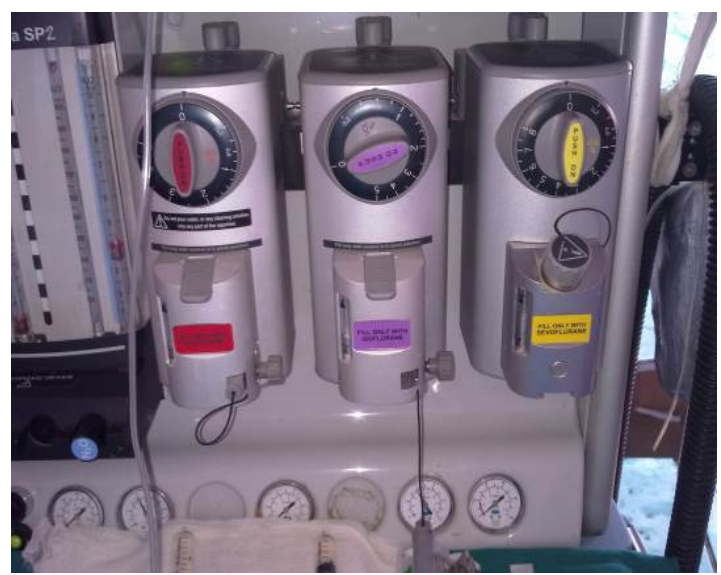

Figure 2

Mamta Bhardwaj, Shashi Kiran, Kiranpreet

Kaur. Department of Anaesthesiology and Critical Care, Pt. B.D. SHARMA University of Health Sciences, Rohtak -124001, India.

\section{References}

1. Meister GC, Becker KE. Jr, Potential fresh gas flow leak through Drager Vapor 19.1 vaporizer with key index fill port. Anaesthesiology. 1993;78:211-2.

http://dx.doi.org/10.1097/00000542199301000-00035
2. Ngan J, Cashen D, Nicols G. Sevoflurane vaporizers. Can J Anesth. 1999;46:200. http://dx.doi.org/10.1007/BF03012564

PMid:10084008

3. Dorsch JA, Dorsch SE. Understanding anesthesia equipment. 5th ed. Philadelphia: Williams and Wilkins; 2008. 181.

4. Lewis SE, Andrews JJ, Long GW. An Unexpected Penlon Sigma Elite Vaporizer Leak Anesthesiology 1999;98(4):1221-4.

5. Russel C, Brockwell, Andrews JJ Inhaled anesthetic delivery systems. In: Miller R.D editor Miller's Anesthesia 7th edition vol. 1. Churchill Livingstone; 2010. p.667-710. 